\title{
The meaning of social climate of learning environments: Some reasons why we do not care enough about it
}

\author{
Mara W. Allodi
}

Received: 26 May 2008/Accepted: 14 January 2009/Published online: 18 May 2010

(C) The Author(s) 2010. This article is published with open access at Springerlink.com

\begin{abstract}
The purpose of this article is to analyse reasons underlying the neglect of social climate in education. It discusses the relevance of the concept of social climate in learning environments, presents evidence for its effects and importance in special-needs and inclusive education, presents differences existing between settings and discusses the contribution of social climate to teachers' professional autonomy. The arguments support the view that social climate is an essential factor in educational processes and make incomprehensible the sparse attention given to it in educational policy, research and teacher education programs. Indications of neglect in the Swedish context are presented. The resistance towards the concept of social climate is related to: dualistic and hierarchical views; characteristics of bureaucratic systems; reductionist interpretations; difficulties in handling and evaluating social values and goals; and post-modern criticism of scientific knowledge and psychology. Implications for counteracting reductive interpretations and meeting resistance and criticism are discussed.
\end{abstract}

Keywords Educational research - Interpersonal relationships - Learning environment . Social climate $\cdot$ Teacher education

\section{Background}

The social climate in educational settings is shaped by the relationships between teachers and pupils and among pupils. The quality, quantity and directions of these relationships further affect pupils' self-concept, motivation and performance (Fraser 1986).

The concept of social climate is closely related to classroom climate, school climate and school ethos, and refers to characteristics of the psychosocial environment of educational settings. Interpersonal relationships, student-teacher relationship, peer relationships, teachers' beliefs and behaviours, teachers' communication style, classroom management and group processes are themes that can be considered to be included in the concept of the

M. W. Allodi ( $₫)$

Department of Special Education, Stockholm University, 10691 Stockholm, Sweden

e-mail: mara.allodi@specped.su.se 
social climate of learning environments. Other concepts relevant for the study of social climate in learning environments are self-efficacy, self-concept, trust, goal structures and values, cooperation and competition, participation and exclusion, hierarchy and democracy.

Recently, a model of the social climate of learning environment has been developed as a synthesis of Moos' (1979) theory of psychosocial environments, Schwartz's (1992) conceptualisation of universal human values, and Swedish pupils' evaluations of their learning environments (Allodi 2007a). The model can be used to describe and assess learning environments. Its components are creativity, stimulation, achievement, efficacy, safety, control, helpfulness, participation, responsibility and influence, which are structured in a circular way with the two polarising facets of self-transcendence/self-enhancement and openness to change conservation (Allodi 2007a).

In this article, the relevance of the concept of the social climate of learning environments is described with support from results from educational theory and research; evidence of resistance towards this issue is presented, with examples from the Swedish context; and reasons for disregarding the issue and associated difficulties are suggested.

\section{Relevance: Effects, needs and differences}

Empirical studies and national evaluations show differences between schools in their social climate or ethos. Longitudinal studies, cross-sectional studies and international studies demonstrate that social climate has short-term and long-term effects on pupils' well being, school results and even their employment rates after school (Rutter 2000). Several studies have investigated the association between student outcomes and classroom environment and concluded that "student outcomes might be improved by creating learning environments found empirically to be conducive to learning" (Fraser 1991, p. 13).

Longitudinal and retrospective studies of antisocial behaviour among Swedish youth show that a school's organisation and ethos are important factors in preventing the development of antisocial behaviour. The reforms and cutbacks introduced in the last 15 years, however, might have contributed to diminished preventive interventions and special services, because of reduced expenditures on school health services, lack of special educational competence, and lack of cooperation between professionals from health services and educational services (Rydelius 1996, 2005).

A meta-analysis of 17 longitudinal and cross-sectional multilevel studies concluded that there is a school effect on pupils' results and well-being. School climate is one of the school factors that is related to well-being (Sellström and Bremberg 2006).

The effectiveness of cooperative, competitive and individualistic goal structures in promoting achievement and peer-relationship were studied in a meta-analysis of 148 studies (Roseth et al. 2008). The conclusion was that cooperative goal structures were associated with both higher achievement and positive peer-relationships. This gives support to the theory that positive social relationships could be not only the result of cooperative structures, but also one of the processes contributing to higher achievement.

Social climate and special needs

The development of a favourable classroom and school climate is particularly important in special-needs education, inclusive education and prevention programs. A responsive and respectful social climate at school can motivate pupils from diverse or disadvantaged backgrounds to participate actively in the educative process and to achieve good results. 
The classroom climate can have a causal role in children's problems. Changes in classroom environment were accompanied by a reduction in the occurrence of individuals' aggressive behaviour in randomised intervention trial. The preventive intervention effect (i.e. reducing aggressive behaviour among the more aggressive males) involved reducing the level of classroom aggression (Kellam et al. 1998; Mooij 1999). The authors criticise the educational policy of tracking and ability grouping, because it leads to classrooms with a prevailing disruptive environment. The intervention showed that placing many aggressive males together was related to serious aggressive behaviour later in life, and it could be considered as a measure that socialised children directly towards anti-social outcomes (Kellam et al. 1998).

Pupils with emotional and behavioural problems are also more vulnerable to the negative effects of a poor classroom climate, according to a follow-up study of the effect of poor climate on boys' and girls' externalising and internalising behaviour in a population-based study in Finland (Somersalo et al. 2002). The schools' social environment affected several emotional and behavioural outcomes in other studies with young adolescents, showing that positive perceptions of school climate are a protective factor: they moderate the negative effects of self-criticism on internalising and externalising problems (Kuperminc et al. 1997, 2001).

While all pupils can take advantage of a positive classroom climate, pupils who are more vulnerable need a good social climate in order to thrive at school. In other words, a social climate of medium quality is possibly acceptable for a large group of pupils, but not for all pupils. Inclusive education, with its increasing heterogeneity in educational settings, means that the teachers are expected to refine and develop further their ability to shape in their groups an optimal social climate that is suited for all the pupils in the group, and not only for a resilient majority. Teachers working in inclusive educational settings, where pupils with severe disabilities satisfactorily complete their education together with nondisabled pupils, report that their first strategy is shaping a strong and positive emotional climate in the group (Speltini and Buzzi 1996). The positive emotional climate is continuously developed and kept alive with intentional strategies whenever difficulties arise. Being at school has to be a positive emotional experience, and this is the first requirement for making learning possible. This need is perhaps more self-evident when the child has multiple impairments and severe cognitive disabilities, but the same could be said for every pupil.

The goal of inclusive education seems sometimes difficult to achieve. In the last 15 years, the number of pupils registered in special units (for pupils with mild intellectual disabilities and autism) or enrolled in more flexible special classes has increased in many municipalities in Sweden and overall in the country. Among the reasons for this increase, we can find the introduction of a new outcomes-focused curriculum with an emphasis on minimum standards, together with the decentralisation, deregulation and rationalisation of the educational organisation (Allodi 2007b). But several studies that investigated the experiences and the reasons underlying the decision to attend a special unit or group testify that the main reason in certain cases could be that the pupils were bullied or not accepted in the regular setting, or needed protection from negative attitudes and behaviour from classmates (Allodi and Fischbein 2000). Improving the quality of the learning environment through its social climate can be considered in these cases as a special educational intervention that can make the goal of inclusive education real. An intervention can be necessary in order to enforce and sustain good interaction processes in the group.

The increase in the number of pupils in special educational settings, though, indicates that the strategy of pulling out vulnerable pupils from regular educational settings with 
mediocre- or poor-quality social climates is still widespread. In many cases, this strategy seems to be preferred to making powerful interventions for adapting the regular learning environments to the needs of all children or to the requirements that an inclusive setting must have.

\section{Differences}

An analysis of students' engagement and literacy results in 43 countries, based on large and nationally-representative samples of 15-year-old students from PISA 2000 (Organisation for Economic Co-operation and Development [OECD] 2003), concluded that there is a high prevalence of students who are disaffected from school, that the prevalence varies significantly among schools, and that it is influenced by school policies and local practices. Schools have higher levels of students' engagement when there is a positive climate, good relations between teachers and students, and high expectations for students' success. Teachers and principals can play a strong role in creating a positive culture at school. The importance of engagement is discussed for its association with other positive outcomes, such as well-being and quality of school life. Schools with high levels of engagement among the students did not achieve it at the expense of literacy skills: high student engagement was associated on average with higher literacy skills. (For other analyses of climate factors and students' results in several domains, see Organisation for Economic Co-operation and Development [OECD] 2004.)

Several studies of the psychosocial climate of Swedish educational settings show great variation among classrooms in pupils' perceptions of their learning environments (Allodi $2002 b$ ). The differences were related both to contextual factors and to internal organisational factors. There are indications that differences between schools in the recently highlydecentralised Swedish educational system have increased even more during the past 10 years. Indicators of educational quality have been discussed by Gustafsson (2006). His analysis of national statistics shows that the variations between and within the municipalities on several quality indicators (resources, teachers' competence, educational background segregation) have increased as a consequence of administrative decentralisation and the introduction of parental school choice. Therefore, it is highly likely that variations in the social climate have also increased. The scope for local adaptation is great: schools may adopt their own strategies and organisational models within the scope of the national curriculum and local educational policy.

\section{A bottom-up perspective}

There is a need to develop educational practice based on knowledge that is developed in the field and supported by research. This also means developing and establishing professional knowledge needed to assist occasional trends or educational policies inspired by narrow-minded definitions of the educational mission (Fischman et al. 2006). The top-down perspective on education is obviously legitimate, in the sense that the public educational system in a democratic society has the mission of serving the needs of the surrounding society and the well-being of all its citizens.

However, a dominant top-down view of the educational system as a state apparatus might lead to the belief that teachers are nothing else than bureaucrats blindly following curricula. This view has to be counteracted with energy because it will certainly lead to a deterioration of the quality of education. Awareness of social climate issues in educational setting, on the other hand, can strengthen teachers in keeping a focus on what matters in 
their educational practice, beyond the salvation promises or the technical mirages of the very last educational policies. These policies admittedly are mainly well-intentioned, but they often portray a one-sided emphasis on some educational aspects and tend to forget others, in cyclic and rather global processes of reform trends (e.g. from progressive education to basic knowledge, or from equity to excellence, from control to deregulation, back and forth). The goals that dominate at this moment can lead to unintended side effects, and it is advantageous when reflective teachers are capable of weighting the new trends with their experience in the educational practice, in a bottom-up perspective.

Knowledge and awareness of the importance of interaction processes and relationships in education, in this way, can strengthen teachers in their autonomy, helping in maintaining critical professional insight, and holding out against the utopian starry-eyed promises of perfection that can characterise well-intentioned, but sometimes one-sided, educational reforms.

\section{Some evidence of neglect}

The social climate, the quality and quantity of relationships established in the learning environment, is recognised as an essential factor in the educational process. This view is supported by a large body of evidence from research on classroom climate, self-efficacy, effective schools, inclusive education, special needs, classroom management, and wellbeing and health. Accordingly, it would be very appropriate to adopt and spread widely the principles emerging into educational policies and teacher education. They could contribute to improving educational results, favouring successful inclusive education, and preventing school failure, bullying, drop out, psychological illness and so on.

However, it does not always seem so easy to implement these principles in educational organisations. Even in teacher training programs, these themes are not always considered important. Sometimes they are barely covered by literature in teacher education. This phenomenon is not new and has been observed before in other educational contexts: "Despite the fact that the thriving field of psychosocial learning environment furnishes a number of ideas and techniques which potentially are extremely valuable for inclusion in teacher education programs, surprisingly little progress has been made in incorporating these ideas into teacher education" (Fraser 1991, p. 23).

The prescribed literature in Swedish teacher training programs does not necessarily discuss exhaustively theory and research on classroom climate in learning environments, school ethos or classroom management. Even at the advanced level, such as in special education, it isn't certain that the obligatory literature would cover these themes, relating them to the content of special needs, inclusive education, prevention and intervention.

As an example, a review of the literature in mandatory courses ( 90 European Credit Transfer and Accumulation System [ECTS], corresponding to three terms full-time studies) from one of the major Swedish teacher-training programs was performed. It shows that 7.5 ECTS are devoted to literature on individual development and socialisation in a course with the same name; the main focus of the literature here is on child development and psychology, and not specifically on interactions in educational settings, with the exception of one book on bullying. Further, a mandatory course in Special Education declares the intention to discuss the teacher's leadership and classroom climate in heterogeneous educational settings in its description of goals, but the required reading does not reflect this intention adequately. The other mandatory courses treat entirely different subjects. 
It is possible that the situation is different in other Swedish teacher programs because universities are free to decide the content of their teacher-training courses. It is also possible that teachers discuss with their students issues that are not reflected in the prescribed reading (e.g. in connection with their practical training). However, from this example, we can conclude that the inclusion of classroom climate studies is not guaranteed in the Swedish curriculum for teachers.

The National Agency for Education (Skolverket) publishes reports and other materials on various educational themes. A search in this publication database, containing 1,285 documents, using the Swedish terms for classroom climate, school climate, social climate and bullying was performed. It gave one hit for social climate (National Agency of Education [NAE] 2003), one hit for classroom climate (National Agency of Education [NAE] 2006) and 12 hits for bullying.

Another way to look at the relevance of the themes of classroom climate, and its related fields in the educational debate, is to look at the contents of the research programs that received grants from the Swedish Research Council (SRC 2008) in the subject of Educational Science in the last 7 years, when the Council distributed funds specifically intended for educational research.

A review of the project database gives 290 hits: 25 of these have a title or a short project description indicating that they treat issues at least broadly related to physical and social learning environments, school climate, classroom climate, interactions and relations, teachers' role and strategies, participation and exclusion, or organisation and values in educational settings. Of these 25 programs, there are only four programs (1.3\%) that seems to have-when reading their short description-their main focus on the psychosocial aspects of educational settings, or classroom climate, in primary and secondary education, and for which organisational or didactic issues, subject-related motives, or the physical environment are not the main issues.

Considering the tendencies that seem corroborated by these analyses, it could be relevant to attempt to understand the reasons underlying this neglect of social climate issues occurring in the educational field. This disregard appears quite strange if we consider its recognised value emerging from research.

\section{Aim and method}

The aim of this article is to analyse the reasons underlying the present sparse attention devoted to the concept of classroom climate, or the social climate of learning environments, in the fields of educational research and teacher education, in spite of the evidence from several fields of research that testifies to the importance of classroom climate for students' well-being and outcomes and education quality.

The learning environment is a context for students' learning processes, but can be placed in a broader context, if we consider its interplay with other external factors in an integrated systems framework. For instance, Moos (1991) suggested that a relevant task for the study of learning environments is investigation of the complex connections between school, work and family settings. The aim of this study is similar, in the sense that it also looks at the interplay of factors at various levels in the educational system. One difference is that the object of this analysis is not the social climate of learning environments as an observable phenomenon, but rather the concept of social climate itself. The aim is to describe how conceptions of social climate (e.g. beliefs about or attitudes towards social climate in educational settings) are influenced by contextual factors, and by their interplay 
in the educational system, seen in a continuum involving the micro-level, meso-level and macro-level. The multilevel view of the educational system is inspired by Bronfenbrenner's ecological paradigm (1979), in which "the environment was conceptualized as a set of nested structures at four successively more encompassing levels" (Bronfenbrenner 1995, p. 637). "The conception of the environment as a set of regions each contained within the next" (Bronfenbrenner 1979, p. 9), in turn, draws on the theories of Kurt Lewin (1951) and their topological territories. The ecological paradigm is a general model of human development, and its conceptualisation of contexts has been applied in disciplines and fields that have in common the study of person-environment interaction, and the beliefs, processes and structures involved in this interplay (social psychology, sociology, management, organisations and organisational behaviour (e.g. DiMaggio 1991; Johns 2006).

\section{Results}

Dualistic and hierarchic views

I recognise the first cause of neglect in that social climate is a construct that deals with relationships and emotions. Because the educational mission is concerned primarily with learning and instruction, these issues are not considered so important. A dualistic view leads one to consider concepts as classroom climate and social climate in learning environments as somehow opposite to the goals of increased learning quality and good results, an either-or choice, rather than to view them as the intrinsic components of educational quality that they in fact are.

In this way, the neglect has its origin in a basic ideological Cartesian dualism that affects our culture and our thinking, and hence influences our educational systems and practices. This ideological dualism implies that we tend to look at deeply and truly interrelated phenomenon or concepts without recognising their relatedness and connection. We might tend to define them as opposite. These dualistic standpoints in education were described and analysed by Dewey (1916/1997): with a dualistic view of the human being and its thought, we will define mind as opposite to the body, or rationality as opposite to emotion, or thought to action. We also tend to underestimate the importance of the interactions between these aspects.

Dewey (1916/1997) described sharply and exhaustively the 'educational evil' caused by a dualistic view of humankind, knowledge and education. His analysis is still useful in order to understand both the importance of and the resistance to-and maybe the recurrent indifference towards-the relational and emotional aspects of education.

The psychosocial climate of learning environment can be defined or perceived as contrasting with other educational goals related to curriculum content or at least as subordinate and secondary to the core issue of instruction.

The quality of relations that forms part of the above definition of social climate applies also to emotions. Feelings and emotions related to social interactions are experiences inscribed in the body to underlie perception of the self. Despite their basic importance, human emotions are often still considered of less worth than (and also possible to be separated from) human cognition, they are not traditionally considered as primary objects of the pedagogic discourse, and they are emphasised less in educational documents and guidelines. This is understandable and accords with a dualistic and rationalistic view of human beings and of their education. 
The emotional and affective aspects of the educational practice are seldom, if at all, viewed as something to combat, but they are certainly not perceived as being equal in importance to the cognitive aspects of school life. The lived experience of school is an inextricable combination of actions, relations, emotions and thoughts, and not only the cognitive acquisition of curriculum contents.

The indifference towards, or the resistance to the arguments that compel the educational system to improve the social climate is probably related to this deeply-rooted cultural dualism and to its devaluing of emotional aspects, relative to the cognitive. This view is thus dualistic but also hierarchic.

\section{Bureaucratic system}

Further, what makes the social and relational aspects of the educative experience a challenge is that these experiences occur in a bureaucratic educational system. Such rationalised systems emphasise efficient organisational models and, by and large, are inevitable in our public educational systems, but they imply and perhaps enforce a kind of professionally detached relationship that will counteract the requirements of a warm and responsive social climate.

Authentically professional teachers possess the ability to have warm and genuine relationship with their pupils and to establish a group climate that supports positive relationships among the pupils and motivate them to learn. Yet, teachers find themselves in bureaucratic organisations that nowadays tend to define the educational mission narrowly, focusing just the academic standards of the curriculum. Professional relations also might be defined as detached and rational. Thus, some bureaucratic characteristics of the educational system themselves might contradict or hamper the creation of a positive climate and could represent a major inherent contradiction in the educational system that teachers have to understand, handle and often solve on their own (Allodi 2002a; Fischman et al. 2006).

Good relations or rational techniques

The educational system brings together and makes use of two opposite types of authorityas Weber (1947) defined them-the charismatic and the technical-rational. Awareness of this contradiction between the rationality of the educational system and the relational aspects of the social climate could contribute to understanding of difficulties connected with the application of intervention programs aimed at improving the climate or pupils' behaviour. The principles of an intervention might be relevant, but their implementation in a program risks being heavily rationalised and ending up eventually in arid instrumental techniques; the efficacy residing in their qualities and emotional meanings could be lost. The inherent rational and bureaucratic aspects of the system, in other words, can continuously and subtlety counteract attempts to hold a focus on, and build up meaningful symbolic content, in the educational experience. The risk is recurrent and ever-present, even in this present attempt to analyse resistance to social climate.

Social climate or discipline?

Another challenge lies in the possible disciplinarian interpretation of the concept of social climate. Here a risk is to focus one-sidedly on pupil behaviour that is perceived as 
desirable, and consequently to consider the social climate as nothing else than an instrument to enforce discipline.

The ways in which to improve the social climate in educational settings consist of far more than a focus on changing or regulating children's behaviour at school. Instead, it is necessary to consider first the development of aspects in the learning environment that influence pupils' well-being and satisfaction and then directly and indirectly affect their behaviour. Behaviour evolves through the interplay between person and environment. These two elements, person and environment, are still not considered as equally important, as Bronfenbrenner noted: "What we find in practice (...) is a marked asymmetry, a hypertrophy of theory and research focusing on the properties of the person and only the most rudimentary conception and characterization of the environment in which the person is found" (1979, p. 16). The disciplinarian reductive interpretation of social climate can then be related to this disregard of the importance of environmental contributions to behaviour.

Social climate or social competence?

Talking about increasing children's social competence, as some interventions programs have suggested, is also problematic and delicate. The concept of social competence implies that the children are supposed to learn something, in the same way in which they are supposed to learn the content of the curriculum, while social climate is something that is intentionally shaped by educators in the educational environment in interaction with the pupils.

Social competence also might be interpreted, in a restrictive way, as more updated techniques for learning children good manners. Although this might be considered a desirable goal, good manners do not constitute a sufficient condition for shaping a favourable social climate at school. Pupils can show good manners at the same time as they use advanced communicative techniques that make them skilled manipulators. They might be able to control outbursts of aggression and impulsivity, and still be successful at playing cruel power games without open violence, and so on. In these cases, the students can seem to be behaving perfectly and in line with superficial socially-accepted rules. They could apparently show good 'social competence', even if their behaviour could be questionable from a moral viewpoint and definitely does not contribute to a favourable social climate. The avoidance or prevention of violent behaviour in the school environment is an important goal, but it would be hypocritical to banish and blame physical violence at school while accepting other more-refined and cultivated expressions of cruelty.

\section{Social climate and civic values}

Social climate is also a medium for transmitting and enforcing important social civic values in the school organisation and everyday life. These are included in the social goals that schools have to accomplish. However, pursuing these goals is perceived as a more problematic issue than is the case for goals in educational subjects.

After more than a decade of work with a goal-based curriculum, Swedish teachers are used to defining and structuring goals related to various competences in school subjects. Yet the corresponding defining and structuring of social goals can be perceived as more problematic. Working with social goals involves personal values, attitudes and beliefs that can differ widely even among teachers in the same group. Because these issues are controversial or personal, the common work necessary to reach agreement might be difficult. 
Common values or relativism?

The ideology of cultural relativism is also challenging the idea that schools should transmit any values at all. Which values can be considered truly common and shareable in multicultural educational settings?

Some teachers might believe that the concept of universal human values is compatible with cultural diversity (admitting, recognising and accepting differences), while others want to emphasise cultural differences and define them as incompatibilities. A consequence in school practice is that the development of common rules and values at school can suffer and can be unconvincing, based only on ideology, perceived as arbitrary and eventually neglected.

One way to escape these potential conflicts is to appeal to a definition of education as consisting only of transmission of knowledge. Yet this is an unfortunate standpoint because, even if the system does absolutely nothing explicit to transmit values and beliefs, transmission does occur anyway despite the passive or undecided intentions of the school staff. The problem in this case is that staff members abdicate the responsibility of choosing, agreeing and enforcing the democratic values that our society expects should inspire public educational institutions.

What is likely to happen in the absence of a clear strategy and shared civic democratic goals among the staff is that other social values and attitudes can be allowed to dominate instead (e.g. hierarchical views of people and of their worth). A rank-order view of human beings based on varying criteria (e.g. resources, status, appearance, power, physical strength) is likely to emerge. This is not so surprising because the educational system and the surrounding society itself contain and enforce these hierarchical aspects more or less explicitly as in the school's grading system.

In the educational system, the function of socialisation to the values of a democratic society appears opposed to the function of selection of the citizens for different social positions.

Further, a global tendency in educational policy has been the introduction of other rules, inspired by market management principles (new public management). These principles sometimes lead to a priority on efficiency (highest production, lowest cost) while disregarding the socialisation mission of education. The values that accompany organisations that give priority to efficiency are economic, and these further contribute to a weakening of an organisation's humanistic and democratic values and goals. Where these economic values dominate, they turn the educational system into an industrial plant, where pupils become standardised products. Granted, these aspects are in a way inevitable in a national educational system that has the important social function of educating youth for the posts for which the community will need them. However, the excessive emphasis on these objectified components generates alienation among staff and pupils alike, particularly among those that fall outside the norm or cannot or will not achieve the standardised goals and become the desired products of the educational process.

\section{Lack of evaluation of social goals}

The problem of transmission of democratic social values through the educational system is also controversial for another reason. This goal is formulated in the national guidelines/ curriculum but, because it is not subject to any national evaluation, it can be considered only to be a good intention. 
In a system as decentralised as the Swedish educational one, the weak enforcement of democratic social goals leads to great variation in its implementation. However, the recent introduction of the Act against discrimination at school (2006: 67 Act Prohibiting Discrimination and Other Degrading Treatment of Children and School Students 2006) can be considered as important, by making educational institutions responsible for fulfilling democratic values in their organisation and expecting them to guarantee, in their practice, respect of everyone's human rights.

On the other hand, evaluation of the goals of building a democratic organisation and environment for learning is not easy to standardise. We have to ask whether top-down control of these goals is at all possible, or even desirable. An organisation cannot be genuinely democratic through pure coercion; this indeed would be a paradoxical situation. Where democratic values are 'forced' into an organisation without real understanding or authentic sharing of their meaning, the outcome will be a ritual and formal accomplishment only with the required goals, but with no substance and only a weak influence on educational practice.

Assessing the learning environment or the pupil?

Teachers are expected to assess their pupils' knowledge, competence and learning processes. They are not always familiar with assessments of quality of learning environments. These practices have not become routine in Swedish primary schools.

A motive that can explain a possible resistance among practitioners towards the issue of learning environments is the possible threat that the assessment of learning environments can represent for schools' reputations and teachers' self-concepts. Many teachers are interested in developing the quality of the learning environment in their classroom, but some might feel anxious about how the results of the assessment would be used. In tightlycontrolled and accountable organisations, where the employees have few opportunities to participate and influence their organisation, there is a risk that the assessment's results could be used to compare and criticise teachers' performances in an unconstructive way.

The disregard of educational and social psychology

In educational research and teacher training programs, the resistance towards classroom climate issues can be nourished by a prevailing general disregard towards content related to educational psychology that is visible, at least in the Swedish context.

Educational and social psychology probably had a greater place in teacher education previously, but it seems that these disciplines no longer occupy a central place in teacher training or in educational research today. Sociological and critical perspectives, sociocultural analysis, policy and curriculum studies, discourse and text analysis, and gender issues occupy a more important place today both in teacher training and in educational research.

Various perspectives on education are certainly necessary and I am not arguing here for their irrelevance. The problem is that the challenging criticism of several post-modern authors towards psychology and scientific knowledge (e.g. Foucault 1961) has resulted in the Swedish educational field in a largely unnecessary and unjust attitude of suspicion towards scientific knowledge in general, and particularly towards educational psychology.

Although challenging criticisms always are stimulating and a basic condition of scientific development, the negative and prejudiced attitude towards scientific knowledge developed in other fields is not only unnecessary, but also it can be dangerous. 
Dogmatism implies that knowledge is given (...) and cannot be questioned. Verifying knowledge or seeking new knowledge is thus not a relevant task. The irrationalism implies that attempts to reach knowledge through rigorous scientific methods are fruitless, since other criteria (rhetoric, argument, convincement and marketing) decide what we believe, not evidence. (Allodi 2002a, p. 35)

The post-modern criticism of Enlightenment's Reason risks a come-back of dogmatism and irrationalism. Even if these consequences were perhaps not meant originally, these effects have been noticed before, for instance by Bourdieau: "Certain post-modern analyses (...) bring out only the honest-to-goodness, irrational rejection of knowledge (...) masked as a rejection of 'positivism' and 'scientism'" (Bourdieu 1996, pp. 256-257, author translation).

These attitudes are flourishing in the Swedish educational field. Besides hampering cooperation between researchers and professionals (defined as positivistic), they might effectively prevent the educational field for appreciating the contribution of understanding of educational processes that can come from these fields of educational psychology, cognitive psychology, social psychology, child and adolescent psychiatry, public health, etc.

A prevalent critical perspective on education can also cause disbelieving attitudes (or, alternatively, total disinterest) towards content that can be seen as embodying reformistand thus naïve-attempts to improve educational practice. Educational researchers inspired mainly by critical theories and frameworks are usually not interested in intervention programs aimed at improvements of educational practices. This choice is obviously legitimate, but a problem arises when the ambition in or the engagement to improve practices are criticised as naïve or paternalistic efforts that deserve to be discouraged and devalued. Such criticism risks ending up quickly in a cynical standpoint. The marginalised position of the issues of social climate, relationships and classroom management can be associated with these more general tendencies in educational research and teacher training.

\section{Reflections and directions for action}

The difficulties and challenges described above can be ascribed or found at various levels of the educational system. The dualistic view of knowledge and education is a cultural phenomenon that influences thinking, policies and practices.

The bureaucratic characteristics of the educational system are features at the organisational level that they can shape conditions for educational practices that can be contradictory and counterproductive. The problems related to some reductive interpretations of social climate (as discipline, or as behaviour management techniques, applied in uninspired ways) could emerge in educational practice. These contradictions could be related to the coexistence and conflict of two distinct authority types in the educational system: the charismatic and the technical-rational.

The relative devaluation of what is assumed to be normative - and thus problematic (i.e. the transmission of civic values through classroom climate, with the uncertainty this can produce) - can be represented in classroom practice, teacher education and educational research. The same is true for the emphasis on assessment and evaluation of pupils' achievements, which is seen as the only way in which to measure educational quality and results. This theme also is often enforced by goals-related educational policies, often aimed 
at control of products and not giving equal emphasis to assessment of the educational context.

The disregard of educational psychology is appearing mainly in educational research and teacher training, but it will affect educational practice in time.

Becoming aware of the types of obstacles that can be found in the educational system can be a first necessary step. Here I will only try to suggest some directions to take in order to change these circumstances.

To begin with, we should develop convincing arguments and evidence against dualistic views of the human being. Positive emotions and interactions are neither subordinate to nor inimical of learning processes, but they are conditions of it. We could get support for this thesis from several fields of inquiry, such as philosophy, but also from multidisciplinary studies of human consciousness, cognition and emotion.

The philosophical discussion of values, judgements, practical actions, morality, normativity and relativism can also be necessary to give new legitimacy not only to the universal claims that are implicit in concepts of social climate and positive relationships, but also to the actions taken for the improvements of the quality of educational settings. This legitimacy has been partially lost, or it is questioned at least, under the influence of relativistic, sceptical or nihilistic theories. We should go further and demonstrate why these theories can barely be an adequate foundation for educational judgements and pragmatic educational actions.

An awareness of the challenges that a bureaucratic and rationalised system, that prioritised economic efficiency can imply in shaping and keeping alive in organisations meaningful symbolic and personal meanings, humanitarian values and rights, might help teachers and school leaders in employing strategies that actively counteract these risks. Knowledge from organisational and public management theories could contribute to understanding risks, advantages and conditions of effective goal-steered organisations.

The risk of reductionist interpretations of social climate becoming rational and empty techniques or disciplines is always present in the implementation of educational policies, programs and strategies. Unfortunately, simplistic interpretations and applications can give rise to poor results, eventually making teachers and other professionals feel disappointed about these concepts. A way in which to counteract these poor applications maybe is to elicit the active involvement of the staff in interventions. When implementing programs, we should carefully consider the risks of reductionist interpretations and poor applications and we should try to prevent them.

\section{Conclusions}

This article analysed arguments, beliefs and standpoints that openly and directly are used to contest the importance of social climate in educational settings. It also considered a culture that could more indirectly underlie the resistance or indifference towards research in this field, or towards the introduction of this topic in teacher education. These negative circumstances also contribute to making research-based interventions improbable, particularly in decentralised educational practices. A limitation of this study is that the analyses are based on just one specific educational context. Therefore, it could be interesting to investigate with comparative studies whether these analyses are partially or completely applicable in other educational contexts in order to identify possible similarities and differences. 
In summarising, a major and classic source of resistance against classroom climate and related issues comes from a rationalistic stance with its dualistic view, its disregard of the environmental factors, and the risk of emphasis on bureaucratic solutions or reductive interpretations, ending up in empty techniques. This kind of resistance is not new, even if it can take many different shapes. The relatively new challenge is the resistance coming from an irrational stance, with its scepticism against improvements and shared values and its criticism of scientific inquiry. What we do to counteract the rationalistic critique would not necessarily make any impression on the critical remarks originating from irrational standpoints. There is reason to believe that the resistance coming from opposite directions could be even more difficult to handle.

Independently of their opposite motives, resistance or indifference towards knowledge and research on social climate in educational settings will have consequences that hamper the development of an educational climate of good quality, thus ultimately affecting students' results, well-being and behaviour. However, an awareness of the motives behind the resistance towards social climate in educational settings and teacher training could inspire the development of arguments that take account of this complexity and therefore can facilitate initiatives that are more appropriate. Successful change requires addressing both the supportive and opposing forces that are always present in organisations and the links between immediate needs or situations and larger systemic issues (Bradbury et al. 2008). Therefore it seems particularly important to develop collaborative, participatory research and intervention programs, that are based on relevant theories and are truly open to dialogue and exchange with practitioners. Participatory and action research designs involving school staff, students and parents could be appropriate for offering conditions that are necessary to support sustainable processes of change of the social climate in educational organisations.

Acknowledgments This study was partially supported by a grant from the Swedish Council for Working Life and Social Research, registration No 2001-2078 and by a grant from the Swedish Research Council, Registration No 2008-4733.

Open Access This article is distributed under the terms of the Creative Commons Attribution Noncommercial License which permits any noncommercial use, distribution, and reproduction in any medium, provided the original author(s) and source are credited.

\section{References}

Allodi, M. W. (2002a). Support and resistance: Ambivalence in special education (Doctoral dissertation, Studies in Educational Sciences No. 62). Stockholm: HLS-förlag.

Allodi, M. W. (2002b). A two-level analysis of classroom climate in relation to social context, group composition, and organization of special support. Learning Environments Research, 5, 253-274.

Allodi, M. W. (2007a). Assessing the quality of learning environments in Swedish schools: Development and analysis of a theory-based instrument. Learning Environments Research, 10, 157-175.

Allodi, M. W. (2007b). Equal opportunities in educational systems: The case of Sweden. European Journal of Education, 42, 133-146.

Allodi, M. W., \& Fischbein, S. (2000). Boundaries in school: Educational settings for pupils perceived as different. Scandinavian Journal of Disability Research, 2, 63-86.

Bourdieu, P. (1996). Homo academicus. Eslöv, Sweden: B. Östlings bokförl. Symposion.

Bradbury, H., Mirivs, P., Neilsen, E., \& Pasmore, W. (2008). Action research at work: Creating the future following the path from Lewin. In P. Reason \& H. Bradbury (Eds.), The SAGE handbook of action research: Participative inquiry and practice (pp. 77-92). London: Sage publications.

Bronfenbrenner, U. (1979). The ecology of human development: Experiments by nature and design. Cambridge, MA: Harvard University Press. 
Bronfenbrenner, U. (1995). Developmental ecology through space and time: A future perspective. In P. Moen, G. H. Elder Jr, \& K. Lüscher (Eds.), Examining lives in context: Perspectives on the ecology of human development (pp. 619-647). Washington, DC: American Psychological Association.

Dewey, J. (1916/1997). Democracy and education: An introduction to the philosophy of education. New York: The Free Press.

DiMaggio, P. (1991). The micro-macro dilemma in organizational research: Implications of role-system theory. In J. Huber (Ed.), Micro-macro linkages in sociology (pp. 76-98). Newbury Park, CA: Sage.

Fischman, W., DiBara, J. A., \& Gardner, H. (2006). Creating good education against the odds. Cambridge Journal of Education [Special issue: Creativity in Education], 36, 383-398.

Foucault, M. (1961). Folie et déraison: Histoire de la folie à l'âge classique [History of madness]. Paris: Plon.

Fraser, B. J. (1986). Classroom environment. London: Croom Helm.

Fraser, B. J. (1991). Two decades of classroom environment research. In B. J. Fraser \& H. J. Walberg (Eds.), Educational environments. Evaluation, antecedents and consequences (pp. 3-27). Oxford: Pergamon Press.

Gustafsson, J.-E. (2006). Barns utbildningssituation: Bidrag till ett kommunalt barnindex [Children's educational situation: A contribution to a municipal child index]. Stockholm: Save the Children.

Johns, G. (2006). The essential impact of context on organizational behaviour. Academy of Management Review, 31, 386-408.

Kellam, S., Ling, X., Merisca, R., Brown, C., \& Ialongo, N. (1998). The effect of the level of aggression in the first grade classroom on the course and malleability of aggressive behavior into middle school. Development and Psychopathology, 10, 165-185.

Kuperminc, G. P., Leadbeater, B. J., \& Blatt, S. J. (2001). School social climate and individual differences in vulnerability to psychopathology among middle school students. Journal of School Psychology [Special Issue: Schooling and Mental Health Issues], 39, 141-159.

Kuperminc, G., Leadbeater, B., Emmons, C., \& Blatt, S. (1997). Perceived school climate and difficulties in the social adjustment of middle school students. Applied Developmental Science, 1, 76.

Lewin, K. (1951). Field theory in social science: Selected theoretical papers. New York: Harper \& Brothers.

Mooij, T. (1999). Promoting prosocial pupil behaviour: Secondary school intervention and pupil effects. British Journal of Educational Psychology, 69, 479-504.

Moos, R. (1979). Evaluating educational environments. San Francisco: Jossey-Bass.

Moos, R. (1991). Connections between schools, work and family settings. In B. J. Fraser \& H. J. Walberg (Eds.), Educational environments. Evaluation, antecedents and consequences (pp. 29-53). Oxford: Pergamon Press.

National Agency of Education (NAE). (2003). Kränkande handlingar och informella miljöer [Degrading treatments in environments outside the classroom]. Retrieved May 21, 2008, from http://www. skolverket.se/publikationer?id=1150.

National Agency of Education (NAE). (2006). Lusten och möligheten-om lärarens betydelse, arbetssituation och förutsättningar [Delight and possibility—on teacher's importance, work situation and conditions] Retrieved May 21, 2008, from http://www.skolverket.se/publikationer?id=1630.

Organisation for Economic Co-operation and Development (OECD). (2003). Student engagement at school: A sense of belonging and participation-Publications PISA 2000. Retrieved May 19, 2008, from http://www.oecd.org/dataoecd/42/35/33689437.pdf.

Organisation for Economic Co-operation and Development (OECD). (2004). Knowledge and skills for life: First results from PISA 2000-Publications 2000. Retrieved May, 19, 2008, from http://www.oecd. org/dataoecd/44/53/33691596.pdf.

Roseth, C. J., Johnson, D. W., \& Johnson, R. T. (2008). Promoting early adolescents' achievement and peer relationships: The effects of cooperative, competitive, and individualistic goal structures. Psychological Bulletin, 134, 223-246.

Rutter, M. (2000). School effects on pupil progress: Research findings and policy implications. In P. K. Smith \& A. D. Pellegrini (Eds.), Psychology of education: Major themes (Vol. 1, pp. 3-50). London: Falmer Press.

Rydelius, P.-A. (1996). Skolans betydelse för asocialitetsutveckling [The school's role in the development of antisocial behaviour]. In The National Board of Institutional Care (Ed.), Vaird av ungdomar med sociala problem. En forskningsöversikt [Care of youth with social problems. A research overview] (pp. 239-256). Stockholm: Liber utbildning.

Rydelius, P.-A. (2005). En hälsobefrämjande skola [A health supporting school]. Psykisk Hälsa, 2005(1), $16-18$. 
Schwartz, S. H. (1992). Universals in the content and structure of values: Theoretical advances and empirical tests in 20 countries. In M. P. Zanna (Ed.), Advances in experimental psychology (pp. 1-62). London: Academic Press.

Sellström, E., \& Bremberg, S. (2006). Is there a school effect on pupil outcomes? A review of multilevel studies. Journal of Epidemiology and Community Health, 60, 149-155.

Somersalo, H., Solantaus, T., \& Almqvist, F. (2002). Classroom climate and the mental health of primary school children. Nordic Journal of Psychiatry, 56, 285-290.

Speltini, G., \& Buzzi, A. (1996). Esperienze di integrazione. Scuola elementare "Giuseppe Verdi", Collecchio, Italy. [Experiences of integration: Elementary school "Guiseppe Verdi”, Collecchio, Italy]. Video documentation. Unpublished material.

Swedish Research Council (SRC). (2008). Projektdatabas, Vetenskapsrådet [program database, Swedish Research Council]. Retrieved May 14, 2008, from http://vrproj.vr.se/default.asp?funk=s.

Weber, M. (1947). The theory of social and economic organization. New York: Free Press.

2006: 67 Act Prohibiting Discrimination and Other Degrading Treatment of Children and School Students. (2006). Swedish Codes of Statutes. Retrieved April 13, 2010, from http://regeringen.se/content/1/c6/ 06/42/67/4b3714d5.pdf. 